\title{
SOTL Research Design for Assessment of Interventions
}

By Jean Marie Clipperton, Josue Franco, Shane Nordyke, Melissa Shaffer-O'Connell, and Frederick Wood

Faculty are becoming increasingly interested in the science of teaching and learning (SoTL) and working to explore whether specific interventions are associated with a substantive change in learning outcomes (Whitman and Richlin 2007). In this article we lay out different ways faculty might deepen their approach to SoTL through their courses, provide examples for and explanations of these designs, discuss different means of assessing outcomes depending on the types and regularity of courses faculty teach, and provide specific tools for assessment in the context of a Political Science methods course.

\section{Assessments in Practice}

Most Political Science faculty attempt to increase student learning through new course design, a specific intervention in the form of an assignment or activity, or a new course assessment tool, such as an essay or exam. However, how do we measure the success or failure of these changes? There has been little focus on assessment of course interventions in Political Science (Craig 2014), and we were unable to find other work on how to complete assessments specifically within political science, aside from an article focused upon assessing course simulations (Raymond and Usherwood 2013).

Widening our lens beyond political science, assessments often focus on how to assess student learning (Harlen 2019), distinctions between formative and summative assessments (Harlen and James 1997), and how best to structure assessments (Knight 2002). Harlen and James (1997) provide instruction around the distinction between formative and summative assessments and how each functions. Knight (2002) rightly and wisely points out that assessments (both formative and summative) are in a state of 'disarray' and challenges instructors to improve. However, there are no recommendations for how to systematically do so. We provide a simple framework for moving toward assessment of one's assessments as a way to integrate SOTL principles into research on teaching and learning.

\section{Why should you assess your intervention?}

Designing and implementing new pedagogical techniques is a time consuming enterprise. Faculty typically put a significant amount of thought into how to improve student learning or the student experience in their courses. Thinking in advance about assessing these changes provides multiple benefits. 
1. You will have better feedback about whether the intervention is working in the way that you expected (and will likely think a bit more explicitly about the goals and implementation on the front end).

2. You may receive recognition and credit from your institution for the additional work you put in through publication of your work in a SOTL journal.

3. Other faculty can learn from your experience about the relative utility of the technique, improving outcomes for not just your students, but the discipline as a whole.

\section{The Scope and Purpose of SOTL Interventions}

SOTL interventions vary significantly in terms of scope and purpose. A SOTL article might be on a very specific change designed to achieve a specific and narrow goal. For example, will students be more engaged/interested in discussions of podcasts about a relevant course topic than discussions about a peer-reviewed research article. In this case the intervention isn't designed to increase student performance or achieve a specific learning outcome, but focuses specifically on enhancing engagement. Therefore the assessment should be narrowly tailored on focus specifically on assessing student interest/engagement. SOTL research might also be on broader changes. For example, how will converting your research methods course to online delivery affect student mastery of course material? In this case the assessment would be much broader. You might evaluate the difference between students in both mediums on a variety of learning objectives central to the course. This could be done in through a common final exam or performance in a subsequent Capstone/Thesis course. Finally, SOTL research could also assess large programmatic changes to entire majors. Perhaps your department has redesigned your entire curriculum to better achieve desired specific student learning outcomes. For example, you could be focused on improving student writing, increasing LSAT scores, improving job placement outcomes. The appropriate design and measurement for this sort of SOTL project will necessarily be much broader than the assessment of the introduction of podcasts as an alternative to reading assignments. The essential thing to remember is that both your design and your measure should be aligned with the goal(s) of your intervention/change/technique.

\section{Types of Measures}

There are different ways to evaluate the proposed intervention(s) you've selected. Each has their own advantages and disadvantages with some (overall course grades) having more drawbacks relative to others.

\section{A. Grades and Rubrics to assess student deliverables}

a. Assessing course grades is one way to explore student performance in a course, but there can be many elements that contribute to course grades, particularly if the intervention was the inclusion of student engagement/participation. It will not be clear whether student confidence, interest, or understanding deepened during the course by looking at course grades alone as they are not direct measures of learning outcomes. Furthermore, the faculty member is often the person 
administering the intervention, which further complicates things. Because so much goes into course grades, many journals also will not publish research looking at course grades as measures of success.

b. Exceptions may be when looking at grades or performance in subsequent courses, or performance on specific exam questions. For example, if there are questions on the pretest integrated into the final exam, the performance of students on these questions may be used. Similarly, faculty may explore student performance on assignments as they relate to the course learning objectives, for example as done in (McCarthy and Anderson, 2000).

c. Using standardized rubrics that directly assess the course learning objectives can help standardize the comparison between groups of students taking the course.

d. In addition to student performance overall (e.g. mean or median grade), faculty can consider how students performed on the rubric relative to specific interventions in the course and how learning objectives were advanced by the intervention.

\section{B. Teaching Evaluations}

a. Teaching evaluations can provide one means to explore student perceptions of the course. However, there are many factors that contribute to student evaluations, such as the availability of baked goods (Hessler, et al, 2018), gender of the faculty member (Mitchell and Martin, 2018), and race of the faculty member (Basow, Codos, and Martin, 2013). Additionally, student evaluations of courses may not correlate with student learning, if not negatively correlate with future student performance (Carrell and West, 2010).

b. One preferable option to using overall course measures would be to add additional questions to an evaluations that focus on specific learning objectives relative to the intervention, rather than the overall course evaluation. However, this option is not often available available to faculty at all universities and there is a limitation on the number of questions permissible to include (for example, many institutions limit the faculty to three added questions).

\section{Survey Instruments}

a. Employing a standardized instrument can not only help faculty to objectively assess student performance in a course, it can connect the faculty member's research to a broader SoTL literature and advance understanding of how to best improve student learning.

i. Suggested dimensions for the instruments include student confidence, interest, and knowledge.

ii. Can incorporate long answer responses to understand how students perceived the intervention, how it shifted their experience in the course 


\section{Surveying existing approaches}

The following approaches to SoTL range from simply looking at course evaluations to determine effects on student satisfaction to multi-term longitudinal designs that track student learning not only in the course but some time after the course has ended to evaluate retention. We provide an explanation of each of these to clarify possible actions faculty might take in evaluating their pedagogical interventions, but also to help demonstrate the range of possible approaches faculty might take on their SoTL journey. Faculty can consider these as a possible ladder of techniques they might use to deepen and improve the generalizability of their findings. Our approach draws from the description of quasi-experimental research in RealWorld Evaluation: Working Under Budget, Time, Data, and Political Constraints by Bamberger and Mabry.

- Reading/summarizing teaching evaluations

- Posttest project group only

- Pretest-posttest project group

- Pretest-posttest project group

- Posttest project and comparison groups

- Pretest-posttest project group combined with posttest analysis of project and comparison group.

- Pretest-posttest project and comparison groups

- Comprehensive longitudinal design with pre-, midterm, post- and ex-post observations on the project and comparison groups

In each of these approaches, we discuss the following elements: pretest, posttest, and comparison groups. For unity of language, we're discussing these elements using these terms, but the pretest and posttest can be focused on quantitative measures, such as performance on a specific survey instrument or assessment rubric, and/or could include focus groups, student comments, or other qualitative methods to more fully explore how and why the interventions worked. In other words, your pretest and posttests do not need to be actual tests, they could include a variety of quantitative or qualitative approaches.

\section{Approaches and Advantages: Deepening your SOTL practice}

Below, we explore the above practices, providing examples of how one might conduct each method. We also include additional considerations to weigh when pursuing each option.

\section{Reading/summarizing teaching evaluations}

a. You've implemented something new in the course and/or want to establish or compare a baseline. You use, or add additional questions, to your university teaching evaluations. Benefits to this approach include how simple it is to execute at any time -- limited pre-planning is required and the data is easily accessible. 
i. Studies of this type tend to focus on 'student satisfaction' as it is challenging to map the broadly summarized outcome ratings onto specific learning objectives.

ii. However, many themes can arise in the written student evaluations to help shed light on the intervention beyond whether students said something worked or did not as it can provide mechanisms for why or how it worked.

iii. The realizations that come from student evaluations can often provide a great foundation for future SOTL research conducted by you or others. In these instances it is important to share specific details about how you implemented the intervention or technique that you think led to the increase in student satisfaction. This way other faculty can replicate your approach with more comprehensive assessment techniques.

\section{Posttest project group only}

a. You implemented something new in the course that you realize along the way improved outcomes for students so you decide at the end of the semester to do a quick survey about what students thought about that new element. This shouldn't just be student grades in the course.

\section{Prettest-posttest project group}

a. You learned about a great new pedagogical technique at an APSA TLC track and know you want to implement this technique the next time you teach the course. You develop and administer a pre- and posttest to see if the desired learning outcome is actually being achieved. Before the class starts you make sure to get IRB approval at your institution for this research approach so that you can publish your findings.

\section{Posttest project and comparison groups}

a. You and a colleague each have one or more sections of the same course at your institution. There are many similarities in the courses including a standardized set of learning outcomes, syllabus, and text. You decide to incorporate a new approach or technique that will not be incorporated into the other section. You ask your colleague if they would be willing to administer a survey at the end of their course that you will also use in your own to compare student experiences with and without the new approach.

b. You and a colleague each have one or more sections of the same course at your institution. There are many similarities in the courses including a standardized set of learning outcomes, syllabus, and text. You decide to incorporate a new approach or technique that will not be incorporated into the other section. You ask a third colleague/research assistant/or assessment committee to assess final student deliverables (research papers, literature reviews, presentations, etc.) with a standard rubric. You compare student performance on the learning outcome of interest, as measured by the rubric, across the sections.

c. You have multiple sections of the same course in the same semester (could be at the same institution or across institutions). You have the ability to teach the 
course in the same way (same syllabus, assignments, readings, lectures, etc.) You decide to incorporate a new approach or technique that will be incorporated into one section of the course without changing the other section. At the end of the semester you compare student performance/experience through a standard survey or assignment. If you are assessing student performance on an assignment it is through a rubric that specifically addresses the learning outcome you hoped to improve with the new technique and not just student grades. Ideally, you are able to ask a colleague/research assistant/or assessment committee to assess the final student deliverables (research papers, literature reviews, presentations, etc.) with a standard rubric to avoid confirmation bias. You compare student performance on the learning outcome of interest, as measured by the rubric, across the sections.

\section{Pretest-posttest project group combined with posttest analysis of project and comparison group.}

a. This is a combination of the above strategies. You incorporate a pre and post test in the course that you use the new pedagogical technique in and you compare the post-test or student outcomes to a very similar course which did not receive the treatment. This can be a particularly useful strategy when the other section of the course is one you taught in a previous semester. You obviously can't go back and administer the pre and post tests to the control group from the previous semester but you can assess a common final assignment between the two sections in addition to doing a pre-post test comparison in the new iteration of the course. This can also be useful when you are comparing your section to that of another instructor that has a common final assignment but isn't necessarily willing to incorporate your new pre-post test into their course.

6. Pretest-posttest project and comparison groups Advantages are controlling for students in pre/posttest groups and isolate the impact.

a. This strategy utilizes the best of both comparisons (what students gained over the course of a semester and how the outcomes for this course differ from the same course without the treatment).

b. This is the ideal approach if you have multiple sections of the same course operating within one semester or can also be used if you are willing to delay the intervention for a semester/year so that you can collect pre-post data for the class without the intervention.

c. You could also utilize this approach if instead of a new instrument being used to assess the intervention, the course already had formative and summative assessments built in. Perhaps a short writing assignment early in the course compared to a final paper. As long as you are using a standard rubric to compare performance across the sections, this could still be a valid comparison. Again, it is even better if you are able to find an objective evaluator who wasn't involved in the instruction of either course to compare the artifacts.

7. Comprehensive longitudinal design with pre-, post- and ex-post observations on the project and comparison groups. 
a. While offering the ideal situation for being able to isolate the effect of the pedagogical technique, this design is often logistically difficult. It can work very well though if you are in a department that is required to conduct both formative and summative assessments. For example, you might require all of your majors to complete a department capstone, a senior thesis, or complete an exit exam.

b. In this case not only were you able to collect pre and post-test data for both the class with the new technique and a similar class without it, you are also able to assess the desired outcome at some point after the course has finished. This is the only assessment model which allows you to evaluate the persistence of the improvement achieved through the technique. In addition to the other comparisons you have made you would also evaluate the difference in performance on the summative assessment (capstone paper, exit exam) between the students who took the class with the intervention and those that took the class without. This requires that all students are being compared across some common metric and that you are able to track individual students through the process.

c. The ex-post does not have to be at the culmination of the degree. For example, you may lead a study abroad trip that has as one of its goals to increase students' abilities to understand a specific situation from a different cultural perspective. You develop a set of scenario based questions that you administer before the course and after the course and then again 2 months after the course is completed to evaluate the persistence of the effect.

d. While it is unlikely that you would use this process for the addition of a single specific pedagogical technique you have incorporated into an otherwise similar class, it is ideal for a larger change in the overall approach to the course. For example, your department has decided to teach methods in a two course sequence rather than just one, you have converted your methods course to online or hybrid delivery, or you have changed your traditional research methods course to an information literacy course. In these cases we are more likely to expect a persistent difference in student learning than we would if we were just comparing student engagement on a specific topic between reading a research article and listening to a podcast.

\section{Visual representation of Research Designs}

The term "research design" may have different meanings to different scientists. A broad description is: "The research design refers to the overall strategy that you choose to integrate the different components of the study in a coherent and logical way, thereby, ensuring you will effectively address the research problem; it constitutes the blueprint for the collection, 
measurement, and analysis of data. Note that your research problem determines the type of design you should use, not the other way around!"1

However, research design can have a narrower meaning. This narrower description focuses on objects, how objects are selected, how objects are assigned to groups, what the researcher observes about the group(s) of objects, and what treatments, if any, are administered either by the researcher, by chance, or by nature.

The question is how we represent these different elements in a clear and concise way to help facilitate a dialogue between scientists? Several authors (Gorard 2013; Shadish, Cook, and Campbell 2001; Trochim and Donnelly 2005) have utilized the following notation in defining, describing, and weighing the utility of various research designs.

Below is a figure that represents a switching replications research design, one of the more complex research designs.

$$
\text { \. } \begin{array}{llllll}
G 1 & 01 & x & 02 & & 03 \\
G 2 & 01 & - & 02 & \bar{x} & 03
\end{array}
$$

$\mathrm{N}$ represents non-random sample. This means the objects we are observing were not selected at random. An alternative to non-random selection is random selection, which is represented with $\mathrm{R}$.

Next, G represents a group of objects. In the context of this figure, these groups we not selected randomly.

G1 represents Group 1 and G2 represents Group 2. This means we have 2 Groups of objects. The question is how were $\mathrm{G} 1$ and $\mathrm{G} 2$ formed from the non-random sample? There are two ways to form groups: random assignment and non-random assignment. Random assignment is determined by flipping a coin or rolling a die. Non-random assignment can be done using observable or latent attributes of objects to manually assign them to groups.

The Os represent "observations" or "measurements" of the objects. In the switching replications research design, we observe each Group three times.

$\mathrm{X}$ represents treatment. A treatment can be administered by randomly by the researcher (which is denoted $X$ ) or not randomly (which is denoted $[X]$ ).

The underscore symbol (_) represents a blank space for illustrative purposes.

\footnotetext{
${ }^{1}$ See https://libguides.usc.edu/writingguide/researchdesigns, which cites: De Vaus, D. A. Research Design in Social Research. London: SAGE, 2001; Trochim, William M.K. Research Methods Knowledge Base. 2006. Also see http://www.socialresearchmethods.net/kb/desintro.htm and https://nsuworks.nova.edu/cgi/viewcontent.cgi?article=1442\&context=tar
} 
With this notation in mind, the figure is read from left to right. As we read from left to right, time is passing. Thus, for example, $\mathrm{O} 1$ is the first observation of Group 1 and Group 2.
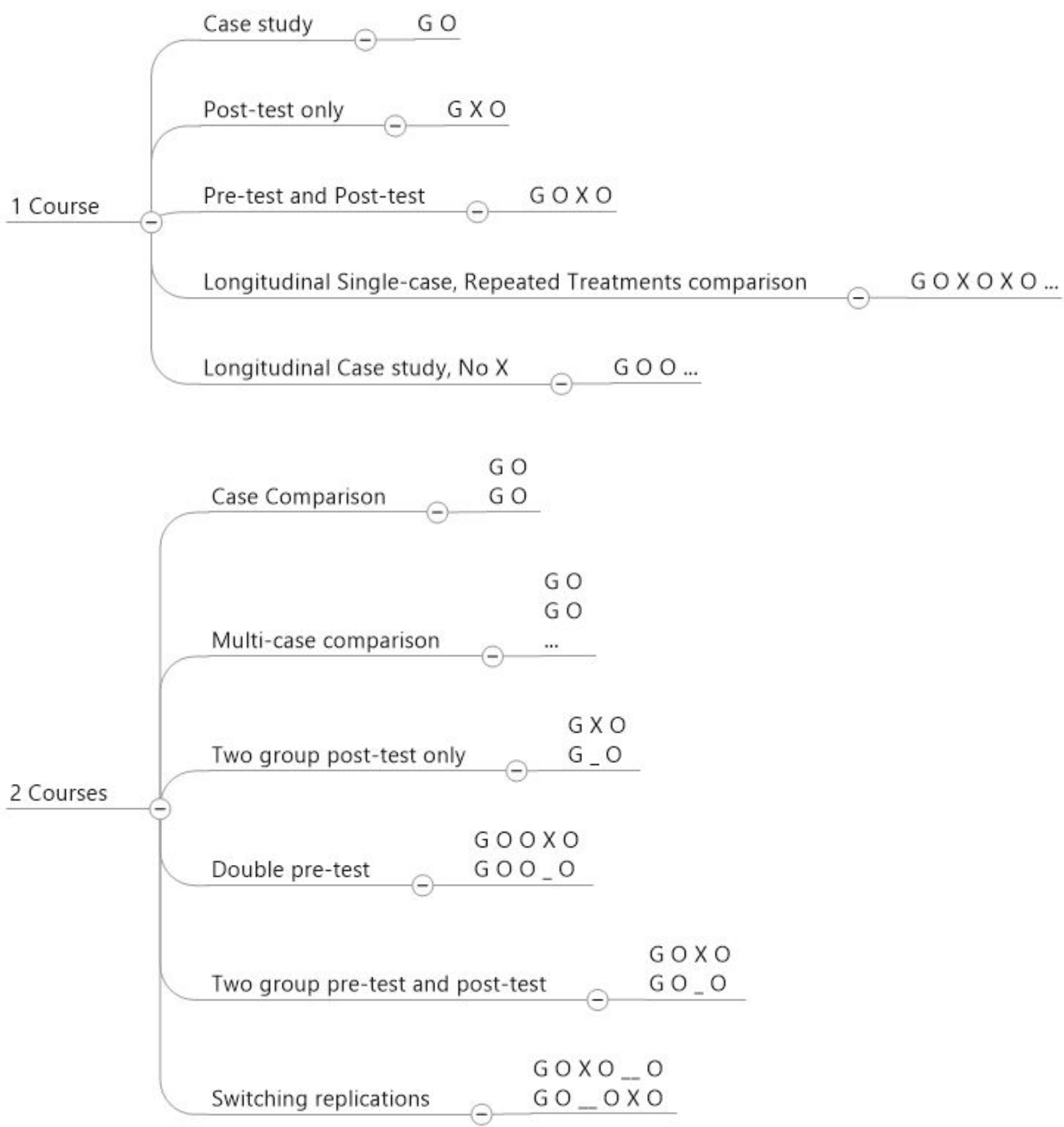

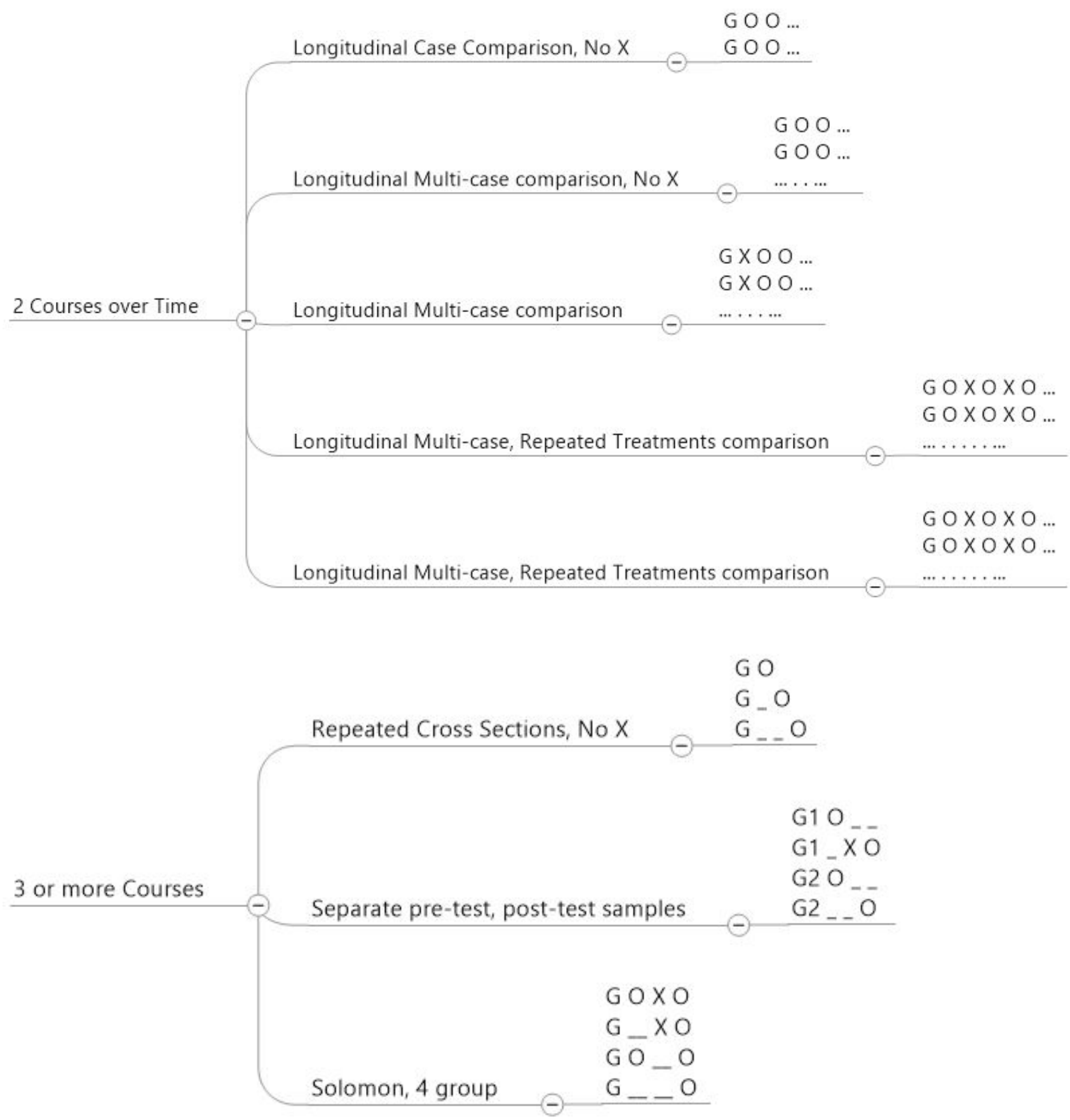

\section{Other Considerations}

Institutional Review Board (IRB): Any educational research that involves interacting with students should go through your institution's IRB board. Typically, but not always, research pertaining to educational purposes is exempt but it must still go through the IRB process. Most journals will not accept research that has not gone through the IRB process. If you do not have 
access to and IRB at your institution, you should make sure that you follow the research ethics guidelines of your institution including adequate human subjects protecitions consistent with APSA Guide To Professional Ethics in Political Science, Chapter III, Section H.

Note that you can improve the scope of your project by connecting to research projects at other institutions through the Consortium for Inter-Campus SoTL Research

(https://www.cmich.edu/colleges/class/Centers/SoTL/Pages/default.aspx).

Randomization - If it is possible to randomize the placement of students to the class with the intervention and the class without, you will be less likely to find spurious effects. In most cases, this isn't possible given that students need to choose the course they are in based on their own schedule, preference for delivery medium, or even preference for instructor.

Controlling for student differences - asking students standardized questions about existing demographic or experiential differences can also help you to control for omitted variable bias. For example, you may by chance have a much greater proportion of female students in one section than in another and it was actually the gender difference that drove the difference in student interest/performance than the pedagogical technique. (Or, for example, you may have just coincidentally had in your treatment class more students who had already taken an advanced math class.)

Controlling for faculty differences - if the intervention is taught in a course with a different instructor than the control section, the observed differences between the two could easily be attributed to the difference in instructors rather than the treatment itself. These differences can be difficult to control for. Increasing the number of observations for both the treatment and control can help to control for these differences. Standardizing the style and approach to the course content can also help. Conversely, having multiple faculty incorporating and assessing the intervention through a pre-post design, can help make the assessment findings more generalizable. We have evidence that the approach works beyond just this one instructor.

Cross-institutional comparisons - Often SOTL research is criticized for being too specific to the context of one institution type. We see remarks such as "Sure that works great on your small liberal arts campus with 15 students in each class but it would never work in my large 150 student sections." There are two approaches to this: 1. Be up front about the context in which this works and you think the findings would be generalizable. There are still plenty of faculty that will be at similar institutions and you are writing specifically for them. 2. If you want to demonstrate that the technique has broader generalizability, which we often do, work with faculty at other institutions to do a cross-institutional comparison. If doing this, it is even more important to have a design which includes a pre-test so that you observe differences that aren't just attributable to differences between the institutions.

Acknowledge the limitations of your approach - There are always things about our approach to SOTL that could be stronger. It is exceptionally rare that we are able to control for everything 
that we would like to. This does not mean that the contribution we are making is not valuable despite these limitations. However, it is important to acknowledge rather than gloss over these limitations. One of the primary critiques of SOTL research by reviewers is "The author fails to acknowledge the limitations of their approach." Be upfront about what you were not able to control for or how the design could be improved and strengthened in future research.

\section{Limitations and Opportunities in Research Design}

Not every researcher has the ability to use more comprehensive SoTL assessment practices due to limitations of their specific teaching situation. Researchers at smaller institutions, for example, may face smaller class sizes, lack of concurrent course offerings, or alternate year courses, while researchers at larger universities may lack the access to students for ex-post assessment. The discussion below is meant to highlight some of the possible limitations and how those limitations may influence choice of assessment designs.

Class Size- Any class size can be used for any assessment design; however, larger class sizes will be more likely to allow control for other variables and to generate significant and generalizable results for designs that only include one class for treatment. In designs that include multiple class sections, smaller class sizes are less of an issue for significant comparisons. For qualitative assessments, such as focus groups or student interviews, smaller class size can be an advantage. Additionally, a qualitative analysis may offset the quantitative deficiencies of a small-n design.

Concurrent Sections of Classes- For assessment designs with a control group, one common design features is concurrent sections of the same class. Control groups can also be used in larger lecture classes with teaching assistant directed break-out sections. Assessment of an individual treatment or assignment could be used with different classes offered concurrently.

Class Offering Frequency- Whether the class is offered every semester, every year, or alternate years does not directly impact assessment design, but it does change the decisions that researchers face in the way they assess the number and degree of treatment changes from class to class. For example, researchers teaching an alternate year class may introduce several new assignments, activities, or features at once to address multiple student learning outcomes. In that case, it may be difficult to isolate the effect of each.

Longitudinal Capability- For a longitudinal study, the ability to offer one or more ex-post assessments at a later date or in a later class is necessary. Longitudinal designs may operate best when the researcher has the ability to interact again with students in a later class, later in their college career, or after they've graduated as this gives the researcher the ability to administer an ex-post assessment. This may be more difficult if the treatment class is a senior level class and the students graduate and move on, if the researcher is at a 2 year institution, or a large institution with rare repeated interactions. 
Course assessment- Course assessment, and the assessment of individual treatments within a single course, compliment other assessment practices in higher education. Most institutions have institutional assessment requirements for programs, schools, and the university. These requirements may influence assessment design decisions. Additionally, course assessment can strengthen and contribute to institutional assessment. Course level assessment results are often integrated into program level assessment and best practices in course level assessment can influence best practices in institutional assessment, whether program level or general education assessment.

Faculty assessment- In addition to institutional assessment, most institutions do regular faculty assessments. Faculty assessment varies from institution to institution, but often includes teaching evaluations, evidence of course assessment, and/or evidence of teaching innovation. SoTL assessment may involve teaching evaluations, frequently contributes to evidence of course assessment, and often is assessment of a teaching innovation.

\section{Concluding Thoughts}

Our goal is to improve our teaching, and we can also contribute to the scholarship of teaching and learning. In doing so, we can assist other faculty in making the same positive changes or avoiding similar difficulties by sharing our teaching innovations. Having rigorous assessment results to bolster our argument for or against a teaching intervention is a key component in assessment and publication. There is no one way to do assessment and what works for one faculty member and may not work for others. The key is to find the assessment that returns the best results and works in academic and teaching environment in which you are working.

\section{References}

Bamberger, M., \& Mabry, L. (2020). RealWorld evaluation: Working under budget, time, data, and political constraints. Los Angeles: Sage.

Basow, S., Codos, S., \& Martin, J. (2013). The effects of professors' race and gender on student evaluations and performance. College Student Journal 47, 352+.

Bishop-Clark, C., \& DietzUhler, B. (2012). Engaging in the scholarship of teaching and learning: A guide to the process, and how to develop a project from start to finish. Sterling, VA: Stylus Publishing.

Carrell, S., \& West, J. (2010). Does professor quality matter? Evidence from random assignment of students to professors. Journal of Political Economy 118(3):409-432. doi: $10.1086 / 653808$.

Consortium for Inter-Campus SoTL Research https://www.cmich.edu/colleges/class/Centers/SoTL/Pages/default.aspx

Craig, J. (2014). What have we been writing about? Patterns and trends in the scholarship of teaching and learning in Political Science. Journal of Political Science Education, 10:23-36.

De Vaus, D. (2001). Research design in social research. London: SAGE. 
Gorard, S. (2013). Research design : Creating robust approaches for the Social Sciences. Thousand Oaks, CA: SAGE.

Harlen, W. (2016). Assessment and the curriculum. In Wyse, D., Hayward, L., \& Pandya, J. (Eds). The sage handbook of curriculum, pedagogy and assessment (693-709). London: SAGE Publications.

Harlen, W. \& James, M. (1997). Assessment and learning: Differences and relationships between formative and summative assessment, Assessment in Education: Principles, Policy \& Practice 4:3, 365-379. DOI: 10.1080/0969594970040304

Hessler, M., Pöpping, D., Hollstein, H., Ohlenburg, H., Arnemann, P., Massoth, C., Seidel, L., Zarbock, A., \& Wenk, M. (2018). Availability of cookies during an academic course session affects evaluation of teaching. Medical Education, 52(10), 1064-1072. http://doi.org/10.1111/medu.13627

Knight, P. (2002). A systemic approach to professional development: learning as practice. Teaching and Teacher Education 18(3), 229-241.

McCarthy, J., \& Anderson, L. (2000). Active learning techniques versus traditional teaching styles: Two experiments from History and Political Science. Innovative Higher Education, 24(4), 279-294. http://doi.org/10.1023/B:IHIE.0000047415.48495.05

Mitchell, K., \& Martin, J. (2018). Gender bias in student evaluations. PS: Political Science \& Politics, 51(3), 648-652. http://doi.org/10.1017/S104909651800001X

Raymond, C. and Usherwood, S. (2013). Assessment in simulations. Journal of Political Science Education, 9(2), pp.157-167.

Shadish, W., Cook,T., \& Campbell, D. (2001). 2 Experimental and quasi-experimental designs for generalized causal inference. 2nd ed. Belmont, CA: Wadsworth Cengage Learning.

Siver, C., \& Haeg, C. (n.d.). The Drunkard's Search: Student Evaluation in Assessing Teaching Effectiveness. Retrieved from https://pdfs.semanticscholar.org/dd40/a6f464164ab0b92b7452e177f1d947b5065d.pdf

Trochim, W., and Donnelly, J. (2005). Research methods knowledge base. 3rd ed. Cincinnati, $\mathrm{OH}$ : Atomic Dog Publishers.

Whitman, P. \& Richlin, L. (2007). The status of the scholarship of teaching and learning in the discipline. International Journal of Scholarship of Teaching and Learning 1(1): 1-17. 